\title{
Comparative Study between Type I and Type II Fuzzy Controller for Semi Active Suspension System
}

\author{
H. Lammari*a, N. Kheznadjia, M.Khodjab ${ }^{b}$, A. Jabbar Hassan ${ }^{a}$ \\ a LMA, USTHB, BP. 32, El-Alia, 16111 Bab-Ezzoaur, Algiers, Algeria \\ bDepartment of Electronics, College of Engineering, Mustaqbal University, Buraidah, 51452, Saudi Arabia. \\ bDepartment of Electrical Engineering, Faculty of Technology, M’sila University
}

\begin{abstract}
$\begin{array}{lllllllllllll}\text { A } & \text { B } & \mathbf{S} & \mathbf{T} & \mathbf{R} & \mathbf{A} & \mathbf{C} & \mathbf{T}\end{array}$
In this article, a type-2 fuzzy interval controller is proposed to solve the nonlinear control problems of semi-active suspension system. A suspension model with two degrees of freedom and A fuzzy approach for controller synthesis were proposed. The performance of the IT2FLC-based semi-active vehicle suspension system in terms of sprung mass displacement, suspension deflection and tire deflection are compared to the homologous fuzzy type-1 controller (T1FLC), and to the passive suspension system conventional using MATLAB / SIMULINK software for simulation and controller design. The vehicle parameters, called suspension deflection and speed of suspended mass are given as inputs for both controllers. The $\mathrm{C}_{\text {semi }}$ control signal is the variable damping coefficient. Inputs and outputs are presented by triangular membership functions. Mamdani inference system is used, along with a Karnik-Mendel algorithm to locate the center of gravity in reduction type for IT2FLC controller. Simulation results show that IT2FLC-based semiactive suspension system outperforms T1FLC and passive suspension system. Thus, they show a major improvement in control signal i.e. IT2FLC controller generates a lower damping coefficient than T1FLC controller. In addition, a remarkable reduction in signal energy by IT2FLC compared to same semi-active suspension system with T1FLC.
\end{abstract}

Keywords: Semi-active and passive suspension, Quarter-vehicle modeling, Type-1 fuzzy logic control, Type- 2 fuzzy logic control,Matlab

\section{INTRODUCTION}

Among indispensable components of a vehicle today are the suspension systems, which play an important role firstly to maintain continuous contact between tires of a vehicle and road for safety driving. Secondly to isolate vehicle's chassis from road disturbances which guarantees passenger comfort.

Semi-active suspension system was introduced in early 1970s by Karnopp [1]. Several studies on semi-active suspensions in order to obtain an appropriate control strategy implemented to provide necessary damping coefficient. The characteristic time varying nonlinearity and uncertainty affect the performance of conventional control strategies [2]. To overcome these problems, an FLC being an intelligent control, can be used to deal with non-linearity and uncertainties.

Vague idea appeared firstlyin 1960s by Pr. Lotfi Zadeh [3]. One of the main advantages of this type of control strategy is that a precise systemdescription is not necessary [4], fuzzy logic controllers (FLC) are recognized to be a feasible methodology to design robust controllers capable to provide satisfactory performance in face of non-linearity, uncertainty and imprecision [5]. These advantages led many researchers choose to examine this type of control strategy (FLC) for either active or semi-active suspension systems to manage the trade-off between ride quality and handling. [6, $7,8]$.

Inherently, at computational level, uncertainties arise in membership functions, rendering type-1 fuzzy systems unable to support them. Thus, it was born the idea of introducing new type-2 fuzzy systems in which the degree of membership of antecedents and / or consequents is itself represented by a fuzzy set between 0 to 1.Type-2 fuzzy sets are useful when it is difficult to determine exact andprecise membership functions [9].

Jiangtao Cao et al [9] have proposed a new adaptive fuzzy logic (AFC) controller based on type-2 fuzzy interval for active suspension for quarter-vehicle system. The adaptive strategy obtained from least means squares optimal algorithm (LMS) is adopted to self-adjust the lower and upper limits of fuzzy membership functions of type 2 interval. Two years later, [5] have operated on new type-2 fuzzy interval controller architecture for half-vehicle models still for active suspension systems. To build this controller they used Takagi - Sugeno (T - S) fuzzy model with type-2 fuzzy interval reasoning, Wu-Mendel uncertainty limit method and optimization algorithms. Subha Celin and Rajeswari [10] have explain the vehicle active suspension system (VASS), T2FLC and GA-T2FLC algorithms are performed, with the T2FLC gains being tuned by an actual encoded genetic algorithm, thus T1FLC is performed (they used same bases of rules previously proposed by Rajeswari [11] but with Gaussian inference functions), the results of his different strategies are compared to the passive system, the study showed the effectiveness of GA-T2FLC. In 2017, [12] examines the emerging role of Adaptive Interval Fuzzy Logic Type-2 (AIT2FLS) versus Adaptive Fuzzy Logic Type-1

*Corresponding Author Institutional Email: gm.lta303@yahoo.fr(H. Lammari)

ISSN: 0010-8189

C CONVERTER 2020

www.converter-magazine.info 
(AT1FLS) in vehicle driving by a new nonlinear model of the Variable Geometry Active Suspension System (VGS) as a complete vehicle. Do Xuan Phua and Van Mien [13] have clarify a quarter of a vehicle a new adaptive controller, it has been proposed based on a type-2 fuzzy model integrated into a neural network to solve the dead-band and delay problems of the actuators. Taghavifar [14] reveals improvement the efficiency of a battery electric vehicle with a powertrain integrated into the wheel, active suspension is investigated by introducing type-2 fuzzy neural network (T2FNN) Kalman filter (EKF).

According to above study, it was concluded that the majority of works have exploited type-2 fuzzy logic aims to control active suspension systems. Present study used of quarter semi-active suspension systems of a vehicle with two degrees of freedom in order to see how to react the fuzzy logic control type-2 compared to the type-1.We have simulated fuzzy controllers (T1FLC and IT2FLC) under Matlab / Simulink environment with two inputs: one is the speed of suspended mass and the other is deflection of suspension. The block output is the damper'scoefficient. The results obtained are compared to the passive suspension system.

Present article is organized as follows: the second section is model description with development of motion equations, the third part presents the control structure adapted in current work, the fourth section is simulated and discussed the results and finally with a conclusion.

\section{MODEL DESCRIPTION}

The semi-active suspension system (SA) was considered to be a good alternative between active and passive suspension system, i.e. reliability and versatility of traditional suspension, and performance of active controlled suspension systems [15]. The conceptual idea of SA suspension is replaced active force actuators with continuously adjustable elements[16].Suspension of vehicle can be modeled as a "quarter car" model,Figure 1.(a): passive suspension. This model has 2 degrees of freedom which represents one of the four corners of the vehicle, it assumes that the vehicle tire does not leave the ground, and that vertical displacement of chassis " $\mathrm{M}_{\mathrm{U}}$ " and tire " $\mathrm{M}_{\mathrm{S}}$ " are measured from their equilibrium position, and the chassis is a rigid body. Quarter car model studies the vertical movement of the vehicle only: $\mathrm{Z}_{1}$ and $\mathrm{Z}_{2}$ are vertical displacements of unsprung mass (chassis) and sprung mass (tire), respectively. $\mathrm{Z}_{0}$ is disturbance due to profile of road.

In the case of a semi-active suspension, variable force element is a shock absorber with variable damping coefficient. There are two ways to model the semi-active suspension systems of vehicle quarter, the first is by conceding that the variable shock absorber " $\mathrm{C}_{\text {Semi }}$ " is placedin parallel with the spring " $\mathrm{K}_{\mathrm{S}}$ "(Figure 1.(b)) [2, 15]. The second by adding a variable damper in parallel to the passive elements: spring " $\mathrm{K}_{\mathrm{S}}$ " and damper " $\mathrm{C}_{\mathrm{S}}$ ", (Figure 1.(c)) [11,17].By connecting the variable damper in this manner the performance of the system is enhanced, by allowing for increased stability of the system.In this study, a quarter-car model has two degrees of freedom as illustrated in Figure 1.(c) was used.

The effect of the tire damping coefficient $\mathrm{C}_{\mathrm{t}}$ is very small compared to the spring stiffness $\mathrm{K}_{\mathrm{t}}$ so it is assumed to be negligible, using Newton's second law of motion, the differential equations describe the dynamics of semi-active suspension and can be written as (see the Equation (1) and(2)).

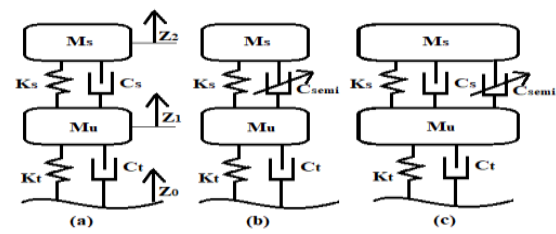

Figure 1. Quarter car passive (a) and semi-active (b),(c) suspension system.

TABLE 1. Dynamic parameters $[17,18]$

\begin{tabular}{lll}
\hline Parameters & Values & Units \\
\hline$M_{U}$ & 36 & $\mathrm{Kg}$ \\
\hline$M_{S}$ & 240 & $\mathrm{Kg}$ \\
\hline$K_{t}$ & 160000 & $\mathrm{~N} / \mathrm{m}$ \\
\hline$K_{S}$ & 16000 & $\mathrm{~N} / \mathrm{m}$ \\
\hline$C_{S}$ & 1000 & $\mathrm{Ns} / \mathrm{m}$ \\
\hline
\end{tabular}

$$
\begin{aligned}
& \mathrm{M}_{\mathrm{U}} \ddot{Z}_{1}=-\mathrm{K}_{\mathrm{t}}\left(\mathrm{Z}_{1}-\mathrm{Z}_{0}\right)+\mathrm{K}_{\mathrm{S}}\left(\mathrm{Z}_{2}-\mathrm{Z}_{1}\right)+\mathrm{C}_{\mathrm{S}}\left(\dot{\mathrm{Z}}_{2}-\dot{\mathrm{Z}}_{1}\right) \\
& +\mathrm{C}_{\mathrm{Semi}}\left(\dot{\mathrm{Z}}_{2}-\dot{\mathrm{Z}}_{1}\right) \\
& \mathrm{M}_{\mathrm{S}} \ddot{Z}_{2}=-\mathrm{K}_{\mathrm{S}}\left(\mathrm{Z}_{2}-\mathrm{Z}_{1}\right)-\mathrm{C}_{\mathrm{S}}\left(\dot{\mathrm{Z}}_{2}-\dot{\mathrm{Z}}_{1}\right)-\mathrm{C}_{\text {Semi }}\left(\dot{\mathrm{Z}}_{2}-\dot{\mathrm{Z}}_{1}\right)
\end{aligned}
$$


where $\mathrm{C}_{\text {semi }}$ is the variable coefficient damper(controlled parameter in the design). The state space equations used in the implementation of the quarter car semi-active suspension systemare written as in Equation (3):

$$
\dot{X}=A X+B X C_{S e m i}+E \dot{Z}_{0}
$$

with:

$$
\begin{aligned}
& X=\left\{\begin{array}{l}
X_{1}=Z_{2}-Z_{1} \\
X_{2}=\dot{Z}_{2} \\
X_{3}=Z_{1}-Z_{0} \\
X_{4}=\dot{Z}_{1}
\end{array} \quad \boldsymbol{A}=\left[\begin{array}{cccc}
\mathbf{O} & \mathbf{1} & \mathbf{0} & -\mathbf{1} \\
\frac{-\boldsymbol{K}_{S}}{\boldsymbol{M}_{S}} & \frac{-C_{S}}{\boldsymbol{M}_{S}} & \mathbf{O} & \frac{C_{S}}{\boldsymbol{M}_{S}} \\
\mathbf{O} & \mathbf{O} & \mathbf{0} \\
\frac{\boldsymbol{K}_{S}}{\boldsymbol{M}_{U}} & \frac{C_{S}}{\boldsymbol{M}_{U}} & \frac{-\boldsymbol{K}_{t}}{\boldsymbol{M}_{U}} & \frac{-C_{S}}{\boldsymbol{M}_{U}}
\end{array}\right]\right. \\
& E=\left[\begin{array}{c}
0 \\
0 \\
-1 \\
0
\end{array}\right] \\
&
\end{aligned}
$$

Where $X_{1}$ is suspension deflection; $X_{2}$ is absolute velocity of sprung mass; $X_{3}$ is tire deflection; and $X_{4}$ is absolute velocity of unsprung mass.

Using above equations, a digital model is simulated under MATLAB / SIMULINK. According to the study of Saad and al. [18], therefore, it's preferable to estimate dynamic parameters for a passive suspension of quarter car according to Chen model(See Table 1).

\section{RECALL ON TYPE I AND TYPE II FUZZY CONTROL}

Type-1 fuzzy logic is a mathematical theory formalized by fuzzy sets, which presents an extension of classical set theory ( 0 or 1). It was introduced in the objectivity to approach human reasoning with help of an adequate representation of knowledge using specific mathematicalfunctions: such as rules base and membership functions, which they are constructed by attribution linguistic and digital information provided by human expert.

Type-2 Fuzzy logic works under concept of type-2 fuzzy sets introduced by Zadeh, and it is an extension of type-1 fuzzy set. The fuzzy set of type-2 is characterized by a fuzzy membership function, i.e. the membership of each element is also a fuzzy set in (0-1), unlike fuzzy set of type-1, where membership is a specific number between (0-1) [19].

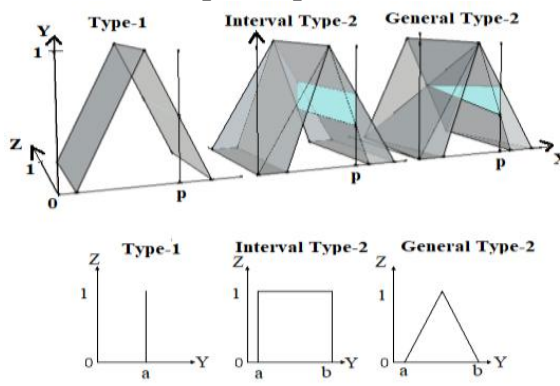

Figure 2. Comparison between fuzzy logic type-1 and type-2 interval and general. [20]

Fuzzy logic type-2 encompasses the generalized type and the interval (see Figure 2). An interval type-2 fuzzy set is a type-2 fuzzy set in which all secondary membership functions are type-1 sets of interval forms, therefore, all secondary memberships are equal to $1[20]$.

3. 1. Type-1 Fuzzy Logic ControlType-1 fuzzy logic controller (T1FLC) has four functional steps summarized in [21]: -Fuzzification: is first step, it transforms each actual (measured) input value into a fuzzy set. The process of fuzzification allows input and output of the system to be expressed in linguistic terms.

-Base of fuzzy rules: is a collection of fuzzy rules of the form "If (X is A) Then (Y is B)"

-The fuzzy inference: that uses the fuzzy rule base to transform from fuzzy sets in input space to fuzzy sets in output space based on fuzzy logic operations.

-Defuzzification is the process that converts fuzzy output to sharp value.

3. 2. Type-2 Fuzzy Logic ControlThe structure of T2FLC is very similar to T1FLC (see Figure 3), with the peculiarity of using a type reducer to convert type- 2 fuzzy sets at the output of the system to inferences in type-1 fuzzy sets before the

ISSN: 0010-8189

(C) CONVERTER 2020

www.converter-magazine.info 
defuzzification phase [22].There are many methods of type reduction, such as centroid, center of sets, and modified height; [23].

In present study, Mamdani method is used for Fuzzy Inference System. And Karnik-Mendel algorithms for locating the center of gravity over type 2 interval set. (see Figure 4).

3. 3. Application On Semi Active Suspension SystemThe vehicle's suspension systems are very complex and nonlinear. The performance of suspension settings change when a vehicle is driven in various road conditions. The main diagram of controller structure in our work is shown in Figure 5.

The vehicle parameters are called the suspension deflection and the velocity of the suspended mass are given as input to the controller, and the force of damper is its output. Each input and output variables are divided into fivetriangularsmembership functions usingfollowing linguistic variables: negative large (NL), negative small (NS), zero (Z), small positive (PS) and large positive (PL). The universe of discourse is normalized to [-1 to 1], see Figure 6.The fuzzy rule bases are in the form of linguistic variables using the fuzzy conditional statement (if... then) are given in Table 2. We used the same rule bases to simulate the two controllers T1FLC and IT2FLC.

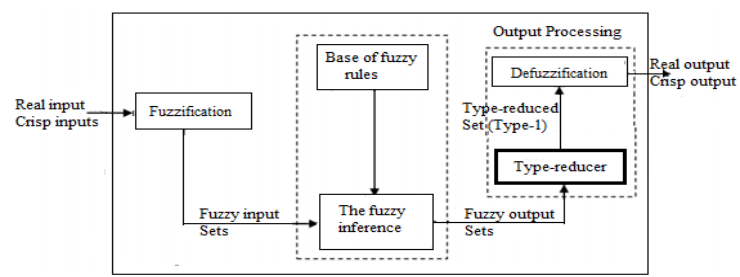

Figure 3.Fuzzy controller type-2 structure.[22]

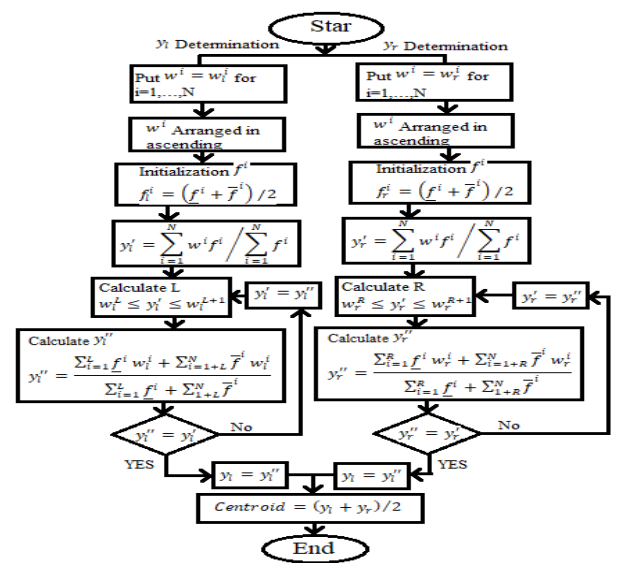

Figure 4. Karnik-Mendel algorithm to locate the centroid of interval type-2. [23]

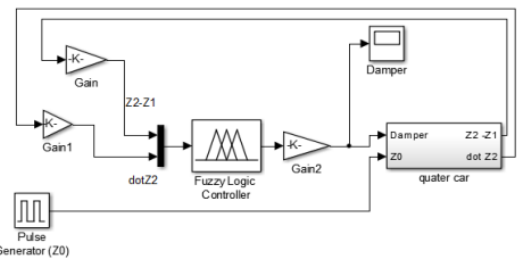

Figure 5. Control diagram of a quarter of a vehicle using fuzzy logic (type-1 and type-2).

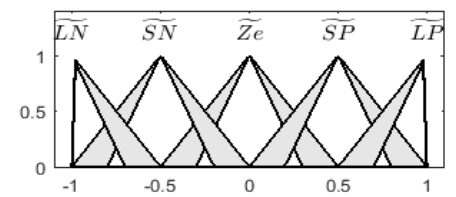

Figure 6. Membership functions of input, output variables IT2FLC.

TABLE 2. Rule base.

\begin{tabular}{|c|c|c|c|c|c|}
\hline & NL & NS & $\mathbf{Z}$ & PS & PL \\
\hline $\mathbf{N L}$ & PL & PL & PL & PS & $\bar{Z}$ \\
\hline $\mathbf{N S}$ & PL & PL & PS & $\mathrm{Z}$ & NS \\
\hline $\mathbf{Z}$ & PL & PS & $\mathrm{Z}$ & NS & NL \\
\hline $\begin{array}{l}\mathbf{P S} \\
\end{array}$ & PS & $\mathrm{Z}$ & NS & NL & NL \\
\hline $\begin{array}{l}\mathbf{P L} \\
\end{array}$ & Z & NS & NL & NL & NL \\
\hline
\end{tabular}

ISSN: 0010-8189

(C) CONVERTER 2020

www.converter-magazine.info 


\section{RESULTS DISCUSION}

This part of study clears the comparison and validation of present work. This study presents simultaneously the results for a passive suspension and those obtained for a semi-active suspension fitted first with a type-1 fuzzy controller (T1FLC) and then a type-2 fuzzy interval controller (IT2FLC).In current simulation, the ground excitation is given by two repeated bumps of amplitudes $0.05 \mathrm{~m}$ on a flat road, the simulation time is $10 \mathrm{~s}$ as shown in Figure 7.

In order to get a clear indication of improved controller performance, two important characteristics of a vehicle suspension are: ride comfort and handling.

1-Driving comfort can be deduced by analyzing the dynamics of the sprung mass:

As can be seen in Figure8, the sprung mass displacement has been clearly reduced by $24.73 \%$ for IT2FLC controller compared to the passive, and by $14.37 \%$ compared to the same system with a T1FLC controller. Thus, a remarkable improvement for the amortization time to return for the steady state.Figure 9, shows the deflection between the sprung mass and the unsprung mass. Noticed that the travel of the suspension in peak-peak amplitude of IT2FLC controller gives a better deflection of $22.57 \%$ compared to T1FLC and of $31.30 \%$ compared to passive suspension.

2-The second characteristic is the handling of the vehicle, which is deduced by analyzing the dynamics of the unsprung mass:

In Figure 10 the displacement of the unsprung mass has been reduced by $43.62 \%$ using the IT2FLC controller compared to the passive suspension system, and a reduction of $17.12 \%$ compared to the system of T1FLC. Thus, remarkable improvements for tire deflection as illustrated in Figure 11.

Figures 12 and 13 explain the variation of the damping coefficient during the simulation time. The damping coefficient is the output of the fuzzy logic controller, i.e. the control signal.IT2FLC controller generates a damping coefficient five times lower than the damping coefficient generated by T1FLC. For IT2FLC the coefficient varies between [-900, 900] $(\mathrm{Ns} / \mathrm{m})$ while for T1FLC varies between [-5000,5000](Ns/m). A soft shock absorber (a shock absorber with a low damping coefficient), which is called a soft suspension isolates the vehicle body from unwanted vibration transmitted by the road to maintain driving comfort.

Thus, the signal energy was calculated, furthermore, IT2FLC was found to be superior to T1FLC and passive system. Table 3, gives the energy of the systems which is calculated by the following formula (Equation(4)) :

$$
E=\int_{-\infty}^{+\infty}|x(t)|^{2} d t
$$

with $\mathrm{x}(\mathrm{t})$ any signal.

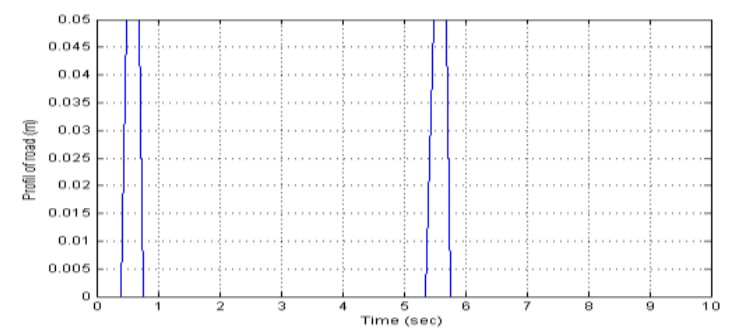

Figure 7.Profil of road $\left(\mathrm{Z}_{0}\right)$.

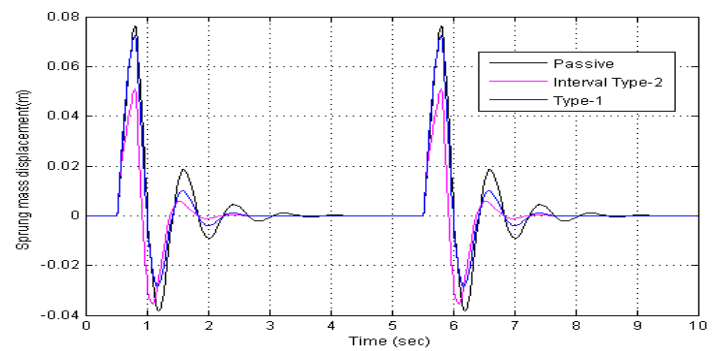

Figure 8.Sprung mass displacement $\left(\mathrm{Z}_{2}\right)$. 


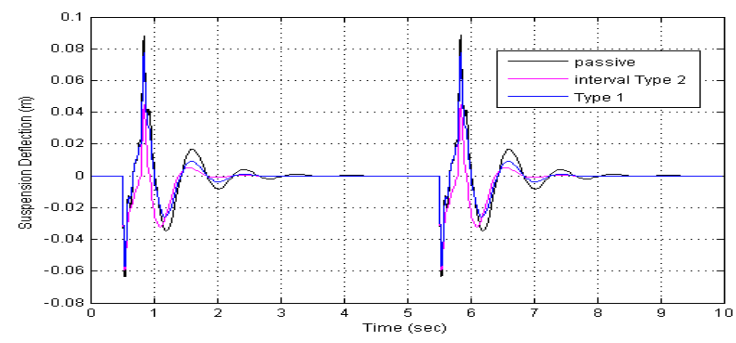

Figure 9.Suspension deflection $\left(\mathrm{Z}_{2}-\mathrm{Z}_{1}\right)$.

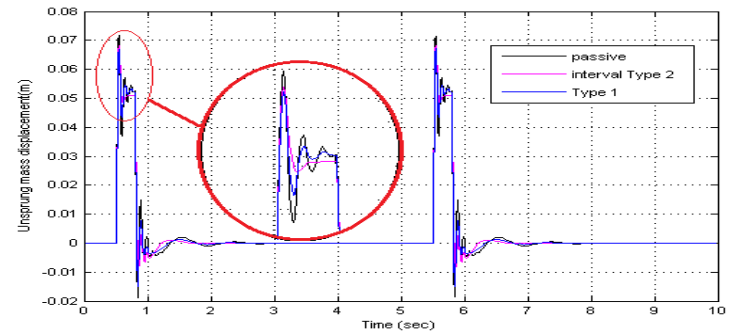

Figure 10.Unsprung mass displacement $\left(\mathrm{Z}_{1}\right)$.

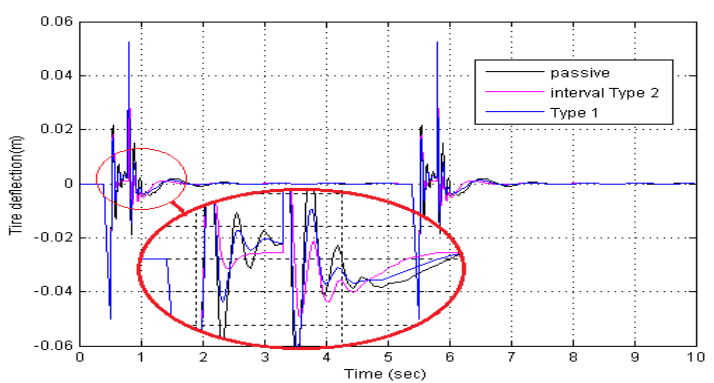

Figure 11. Tire deflection $\left(\mathrm{Z}_{1}-\mathrm{Z}_{0}\right)$.



Figure 12.Variation of the damping coefficient by T1FLC $\left(\mathrm{C}_{\mathrm{semi}}\right)$

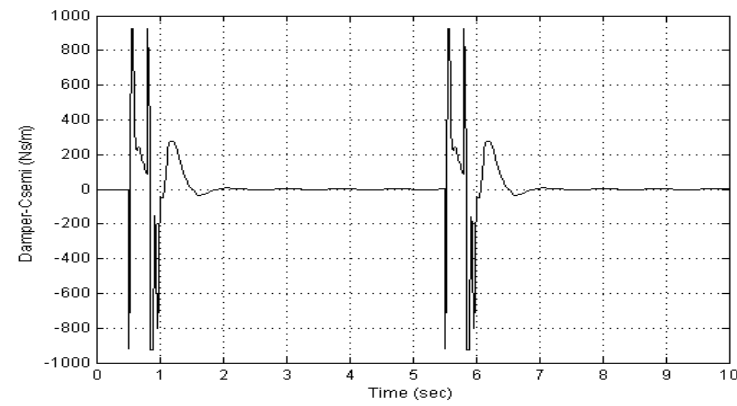

Figure 13.Variation of the damping coefficient by IT2FLC $\left(\mathrm{C}_{\mathrm{semi}}\right)$

TABLE 3.comparison of signal energy between different suspension systems.

\begin{tabular}{ll}
\hline Suspension System & Energy(N.M) \\
\hline Passive & 0.002008 \\
T1FLC & 0.001373 \\
IT2FLC & 0.001036 \\
\hline
\end{tabular}




\section{CONCLUSION}

Present study discusses the central importance of IT2FLC over T1FLC in the control of semi-active suspension of vehicles. The fuzzy logic controller is used to generate the damping coefficient required by the variable damper in semiactive suspension systems. A dynamic model of a quarter of the vehicle is simulated, and a computer program to solve the differential equations of motion in a MATLAB / Simulink environment has been performed. A passive suspension system is adopted for comparison between type-1 fuzzy logic controller and type-2 interval. A Karnik-Mendel algorithm is used to program the type reduction for IT2FLC.

The simulation results explain that, IT2FLC controller significantly reduced the displacement of the sprung mass, the suspension deflection, the tire deflection and generates a low damping coefficient, thus, improved the driving comfort, consequently the vehicle's handling performance by compared to fuzzy type-1 controller counterpart. The Type- 2 Interval Fuzzy Controller is not just much better because it can handle high level uncertainties and improves control performance, but it can also reduce system energy by $24.55 \%$ compared to T1FLC.

It would be very interesting to continue his work by re-testing the IT2FLC control on a more realistic suspension system with several degrees of freedom like the half-vehicle then the whole vehicle while including different microroad profiles.

\section{REFERENCES}

1. Karnopp, D., Crosby, M.J., "Harwood, Vibration Control Using Semi-Active Force Generators", Journal of Engineering for Industry, Vol. 96, No. 2, (1974), 619-626. https://doi.org/10.1115/1.3438373

2. Mulla, A., Unune, D., "Investigating Performance of Quarter-Car Semi-Active Suspension with Skyhook, Fuzzy Logic, Adaptive Neuro-Fuzzy Inference System Control Strategies for ISO-Classified Road Disturbance", SAE International in United States, (2020). https://doi.org/10.4271/2020-01-5040

3. Chevrie F., Guély, F., "Cahier Technique N 191 La Logique Floue", Schneider electric.Edition mars 1998, Code: http://www.schneider-electric.com

4. Toloeia, A.R., Zarchi, M., Attaranb, B., "Optimized Fuzzy Logic for Nonlinear Vibration Control of Aircraft Semi-active Shock Absorber with Input Constraint”, International Journal of Engineering, transactions C: Aspects, Vol. 29, No. 9, (2016) 1300-1306. http://www.ije.ir/article_72797.html

5. Cao, J., Li, P., Liu, H., “An Interval Fuzzy Controller for Vehicle Active Suspension Systems”, IEEE Transactions on Intelligent Transportation Systems, Vol. 11, NO. 4, (2010). DOI: 10.1109 / SEINS.2010.2053358

6. Allam, E., Elbab, H.F., Hady, M.A., Abouel-Seoud, S., "Vibration Control of Active Vehicle Suspension System Using Fuzzy Logic Algorithm", Fuzzy Information and Engineering, Vol. 2, (2010),361-387. https://doi.org/10.1007/s12543-010-0056-3

7. Kurczyk, S., Pawelczyk, M., “Contrôle Flou Pour La Suspension De Véhicule Semi-Actif”, Journal of Low Frequency Noise, Vibration and Active Control, Vol. 32, No. 3, (2013) 217-225. https://doi.org/10.1260/0263-0923.32.3.217

8. Kaldas, M. M.S., Çalışkan, K., Henze, R., Küçükay, F., "Rule Optimized Fuzzy Logic Controller for Full Vehicle SemiActive Suspension”, SAE International in United States, ISSN: 1946-3995, e-ISSN: 1946-4002, (2013). https://doi.org/10.4271/2013-01-0991

9. Cao, J., Liu, H., Li, P., Brown, D., "An Interval Type-2 Fuzzy Logic Controller for Quarter Vehicle Active Suspensions", Proceedings of the Institution of Mechanical Engineers, Part D: Journal of $\begin{array}{lllllll}\text { Automobile Engineering, } & \text { Vol. 222, } & \text { No. } & \text { 8, } & \text { (2008), } & \text { 1361-1373. }\end{array}$ https://doi.org/10.1243\%2F09544070JAUTO767

10. P.Subha Celin, P., Rajeswari, K., "GA Tuned Type-2 Fuzzy Logic Controller for Vehicle Suspension System-active", 2012 International Conference on Computing, Electronics and Electrical Technologies (ICCEET), Nagercoil, India, (2012). DOI: 10.1109/ICCEET.2012.620383

11. Rajeswari, K., Lakshmi, P., "Simulation of Suspension System with Intelligent Active Force Control", 2010 International Conference on Advances in Recent Technologies in Communication and Computing, Kottayam, India, (2010). DOI: 10.1109/ARTCom.2010.21 
12. Baghaeian, M., Akbari, A. A., "Adaptive Interval Type-2 Fuzzy Logic Systems For Vehicle Handling Enhancement By New Nonlinear Model Of Variable Geometry Suspension System", Journal of Vibroengineering, VOL. 19, No. 6, (2017), 4498-4515. https://doi.org/10.21595/jve.2017.17862

13. Phua, D. X., Mienb, V., "Robust control for vibration control systems with dead-zone band and time delay under severe disturbance using adaptive fuzzy neural network", Journal of the Franklin Institute, Vol. 357, No. 17, (2020), 12281-12307. https://doi.org/10.1016/j.jfranklin.2020.09.011

14. Taghavifar, H., "EKF estimation based PID Type-2 fuzzy control of electric cars", Measurement, Vol. 173, (2020). https://doi.org/10.1016/j.measurement.2020.108557

15. Khajavi, M. N., Abdollahi, V., "Comparison between Optimized Passive Vehicle Suspension System and Semi Active Fuzzy Logic Controlled Suspension System Regarding Ride and Handling", International Journal of Mechanical and Mechatronics Engineering Vol.1, No.1, (2007). https://www.researchgate.net/publication/242263877

16. Sulaiman, S., Samin, P. M., Jamaluddin, H., Abd Rahman, R., Burhaumudin, M. S., "Groundhook Control of Semi-Active Suspension for Heavy Vehicle", International Journal of Reasearch in Engineering and Technology. Vol.1, No. 3, (2012), 146-152. https://www.academia.edu/11538863/Groundhook_Control_of_Semi_Active_Suspension_for_Heavy_ Vehicle

17. Chen, Y., "Skyhook Surface Sliding Mode Control on Semi-Active Vehicle Suspension System for Ride Comfort Enhancement", Engineering, Vol. 1, No.1, (2009), 23-32. DOI:10.4236/fr.2009.11004

18. Kashem , S., Ektesabi, M., Nagarajah, R., "Comparison Between Different Sets Of Suspension Parameters And Introduction Of New Modified Skyhook Control Strategy Incorporating Varying Road Condition", Dynamique du système du véhicule Journal international de la mécanique et de la $\begin{array}{lllllll}\text { mobilité des véhicules, Vol. 50, No. 7, } & \text { (2012), } & 1173 & -1190 .\end{array}$ https://doi.org/10.1080/00423114.2012.659743

19. Coupland, S., John, R., "Geometric Type-1 And Type-2 Fuzzy Logic Systems", IEEE Transactions on Fuzzy Systems, Vol. 15, No. 1, (2007), 3-15. DOI: 10.1109/TFUZZ.2006.889764

20. Garibaldi, J., John, R., Wagner, C., "Tutoriel sur le type-2 ensembles et systèmes flous”, IEEE Word Congress on Computational Intelligence, Vancouver, Canada, (2016). https://docplayer.net/39470796-tutorial-on-type-2-fuzzy-sets-and-systems-wcci-2016-vancouver.html

21. Piltan, F., Sulaiman, N., Ferdosali, P., Assadi Talooki , I., "Design Model-free Fuzzy Sliding Mode Control: Applied to Internal Combustion Engine", International Journal of Engineering, Vol. 5, No. 4, (2011). : https://www.researchgate.net/publication/263659466

22. Safaria, A., Hosseini, R., Mazinanib, M., "A Novel Type-2 Adaptive Neuro Fuzzy Inference System Classifier for Modelling Uncertainty in Predictionof Air Pollution Disaster", International Journal of Engineering, transactions B: Applications, Vol. 30, No. 11, (2017) 1746-1751. DOI: 10.5829/ije.2017.30.11b.16

23. Kheir Saadaoui, B. B., Assas, O., Khodja, M. A., "Type-1 and Type-2 fuzzy Sets to Control a Nonlinear Dynamic System", Revue d'Intelligence Artificielle, Vol. 33, No. 1, (2019), 1-7. Doi: https://doi.org/10.18280/ria.330101 